\title{
A Verbal Anchor based Fuzzy System to help business managers build Balanced Scorecards Strategy Maps
}

\author{
Marcelo Ladeira \\ Computer Science Department \\ University of Brasilia \\ mladeira@unb.br
}

\author{
Fernando de Albuquerque Linhares \\ Computer Science Department \\ University of Brasilia \\ falinhares@unb.br
}

\begin{abstract}
The Balanced Scorecard (BSC) methodology was proposed to help companies create simple strategy plans that can be explained to all employees. The core of this tool is the strategy map that shows a collection of strategic objectives a company needs to achieve its mission. Small and medium companies find it difficult to create their own strategies without the help of a management consultant, which is not always affordable. This paper presents the Mistral Solutions, a system that supports entrepreneurs and their teams to create their own BSC initial strategy maps. The system proposed is based on fuzzy logic. Initially the user takes a online survey about his/her enterprise. During the knowledge acquisition a verbal anchor scale can be used to represent numeric information if the entrepreneur does not know the exact values for each question answer. The Mistral Solutions uses the answers to ground fuzzy rules for creating business strategies in the shape of BSC strategy maps. The system proposes eight strategic objectives, two for each of the four classic BSC perspectives. These strategic objectives are chosen from a set of forty-five possibilities. The knowledge base has one-hundred-eleven variables and onehundred-twenty-six fuzzy rules. This system was applied to institutions representing the public sector, the private sector and a public concession. In the empirical evaluation, the system performed better when applied to private sector institution when all the eight strategic objectives were considered adequate by the manager in charge of the strategic planning of this institution.
\end{abstract}

\section{Categories and Subject Descriptors}

I.2 [Artificial Intelligence]: Applications and Expert Systems

\section{General Terms}

Algorithms, Experimentation

Permission to make digital or hard copies of all or part of this work for personal or classroom use is granted without fee provided that copies are not made or distributed for profit or commercial advantage and that copies bear this notice and the full citation on the first page. To copy otherwise, to republish, to post on servers or to redistribute to lists, requires prior specific permission and/or a fee.

SBSI 2015, May 26th-29th, 2015, Goiânia, Goiás, Brazil

Copyright SBC 2015.

\section{Keywords}

Strategy, Fuzzy Systems, Strategy Maps, Balanced Scorecard

\section{INTRODUCTION}

The Balanced Scorecard methodology [8] was introduced by Professors Robert Kaplan and David Norton with a seminar paper that contributed to change the way companies see and handle corporate strategy panels. A Balanced Scorecard can define one company's whole strategy into one dashboard of metrics, targets and initiatives that will drive employees to perform aligned towards a goal: the company's mission. The biggest challenge to most entrepreneurs and managers is to pick the right strategic objectives, metrics and initiatives.

According to Kaplan and Norton [10], in a research done in a universe of one-hundred-forty-three American companies, they found out these results:

- $47.4 \%$ of them do not get to their fourth year

- Only $5 \%$ of the employees understand the word strategy

- Only $25 \%$ of the companies do have incentives (financial or not) connected to strategy

- $85 \%$ of executives spend less than one hour a month discussing strategy

- 9 in 10 fail into executing their plotted strategies

- $60 \%$ of the companies do not create budgets connected to their strategies

Motivated by these difficulties related to implementing strategies at companies, this article presents a fuzzy logic system aligned with verbal anchors to help entrepreneurs pick the right initial strategic objectives for their companies. This web based Balanced Scorecard system system is named Mistral Solutions ${ }^{1}$. It was empirically tested with three companies representing three economics sectors in Brazil with promising results. The companies were a court at the public sector, a civil construction material distribution company at the private sector, and a notary at the concession sector.

In the Section 2 we discuss briefly the state of art on Balanced Scorecard systems, in the Section 3 the approach to build the Mistral Solutions system is presented, and finally in Section 4 the conclusions are presented.

\footnotetext{
${ }^{1}$ www.mistralsolutions.com.br
} 


\section{STATE OF ART}

The papers below focus on the BSC use associated with Artificial Intelligence techniques that allow certain levels of choice of strategy maps.

Kwong and Bai [12] used Fuzzy AHP (Fuzzy Analytic Hierarchy Process) for the development of a quality function, a method of turning qualitative user demands on quantitative parameters. One of the most used methods is the House of Quality that allows outline what factors contribute most to the generation of a product or service quality within a company. In the study it is possible to notice the Fuzzy AHP contribution to sort metrics, but there is no contribution in building a BSC system or to build a strategy or strategy map.

Cebeci [2] proposed the use of Fuzzy AHP together with the BSC for the selection of ERP (Enterprise Resource Planning System) for the textile industry. The use of Fuzzy AHP by the paper was adequate as a multiple criteria decision technique, but does not address how it was built BSC used for the selection of ERP.

Thanaraksakul and Phruksaphanrat [19] used the BSC to make an assessment of suppliers, but without establishing a methodology to determine the BSC or a system to create such an assessment.

Lee, Chen and Chang [1] proposed an approach using Fuzzy AHP to create BSC to evaluate the performance of the information technology departments. The work is focused but in determining the relative importance between the BSC perspectives and which metrics/indicators each perspective should focus on, but does not address the construction of the strategy map itself.

Creamer and Freund [5] proposed the use of decision trees by using the AdaBoost technique, an algorithm created by Yoav Freund and Robert Schapire mining dados that focuses on the automation of setting goals to metrics/performance indicators of companies or corporate governance for typical companies of the S\&P 500 (the 500 largest companies in the United States). The study also indicated that the error variance can be reduced if companies build databases with internal information, which is not always available for use. The study shows the correlation between the use of AdaBoost and the choice of metrics and not help create a strategic map.

Shaverdi, Akbari and Tafti [13] addressed the construction of a BSC with use of Fuzzy AHP associated with MCDM (Decision-making by multiple criteria) to give weights to metrics and evaluate the performance of three non-government banks. The study considers that the MCDM association with the BSC is suitable for evaluation and comparison companies but does not establish a system to analyze this comparison automatically and focuses only on metrics.

Mousakhani, Rahmani and Hamidi [15] used Fuzzy AHP to sort the theory five hospitals using different quality standards through its implented BSCs, given an existing strategic plan and defined through the use of Fuzzy AHP without the implementation of a system.

Abdolshaha, Javidniab, Ali Astanbousb and Eslamic [14] also used Fuzzy AHP to order strategic objectives previously defined in a BSC, but have not created a system to define these goals and neither implemented.

In the last two studies [15] [14] the focus is on comparing existing strategy maps. Our focus is on building an initial strategy map for a company.
Heydariyeha, Javidniab and Mehdiabadib [18] proposed instead of Fuzzy AHP, the use of Fuzzy Dematel, another technique to order different items to assess BSC. Also, this work shows the result without implementing a system or inform how the BSC was obtained.

Considering the survey of the state of the art, we did not find any work that has focused on the use of Fuzzy Logic for building strategy maps and which has implemented this solution as a system available on a web site.

There are some tools that help managers to create a strategy plan. Among them are: SWOT analysis [7], that focuses on finding strengths, weaknesses, opportunities, and threats of a company, but it is criticized ${ }^{2}$ as a tool that some users found it difficult to translate the results into meaningful actions that could be adopted within the wider corporate strategy.

Porter Five Forces [16], that focuses on analyzing the threat of new entrants and substitute products or services, bargaining power of suppliers and buyers and rivalry among existing competitors. Among the criticism on this tool usage there is [4]:

- buyers, competitors, and suppliers are unrelated and do not interact and collude.

- the source of value is structural advantage (creating barriers to entry).

- uncertainty is low, allowing participants in a market to plan for and respond to competitive behavior

Blue ocean strategy [11] is an exercise to create a whole new uncontested market where your company can survive and compete alone. These Blue Oceans would create a leap in value to the company. This strategy approach is criticized due to it is lack until now to generate more case studies than Nitendo DS case and that the Blue Ocean was an attempt to get know set concepts and attach them to a "sticky idea". 3

There are several other frameworks that can help shaping a company's strategy, but until now, there is only one methodology that was able to summarize all these exercises into on concise dashboard capable to tell the whole story and also capable to keep the track of its progress through measurements: the Balanced Scorecard.

The Balanced Scorecard methodology [9] can be briefly summarized to these steps:

1. A company needs to have a Vision.

2. Establish your Mission, which is bringing your Vision to a tangible short two to five year range.

3. Define your values.

4. Establish your perspectives. The typical Balanced Scorecard have four perspectives:

(a) Learning and Innovation. How do we prepare our employees and how do we innovate daily so we can be ahead in our business?

\footnotetext{
${ }^{2}$ http://www.usfca.edu/fac_staff/weihrichh/docs/tows.pdf ${ }^{3}$ http://www.ribbonfarm.com/2007/08/06/book-reviewblue-ocean-strategy/
} 
(b) Internal processes. If we succeed into learning and innovation how can we have excellent internal processes, so we will have a lean company, or a company that have processes that will flow flawlessly

(c) Client. If we have excellent internal processes, what can we do to keep and attract new clients all the time?

(d) Financial. If we have loyal clients, how can we excel financially?

5. For each perspective, define your strategic objectives.

6. Define metrics and targets for the strategic objectives.

7. Create you initiatives for achieving targets.

8. Measure results.

The Figure 1 summarizes the result of using this method to create a Balanced Scorecard:

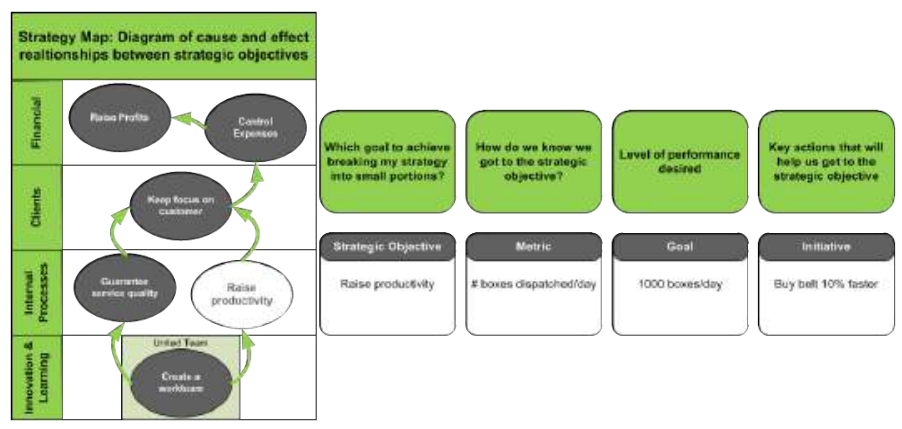

Figure 1: A Balanced Scorecard Example

The Table 1 presents a comparison of the actual systems in the market used in strategy planning according to the BSC methodology. Plans and presentations are used in $66 \%$ of cases. The Palladium ESM is a short for "Palladium Executive Strategy Manager". Map (on the third column) is a short for "Strategy Map". BSC (on the fifth column) is a short for "Helps build BSC". The Mistral Solutions stands as the only one to propose the initial strategy map to the user.

Table 1: A Comparison Between BSC Systems

\begin{tabular}{|l|c|c|c|c|}
\hline System & Dashboard & Map & Metrics & BSC \\
\hline Plans & Yes & No & Yes & No \\
\hline SAP BI & Yes & Yes & Yes & No \\
\hline Oracle Hyperion & Yes & Yes & Yes & No \\
\hline Ibm Cognos & Yes & Yes & Yes & No \\
\hline Palladium ESM & Yes & Yes & Yes & No \\
\hline Stratec & Yes & Yes & Yes & No \\
\hline Quickscore & Yes & Yes & Yes & No \\
\hline BSC Designer & Yes & Yes & Yes & No \\
\hline
\end{tabular}




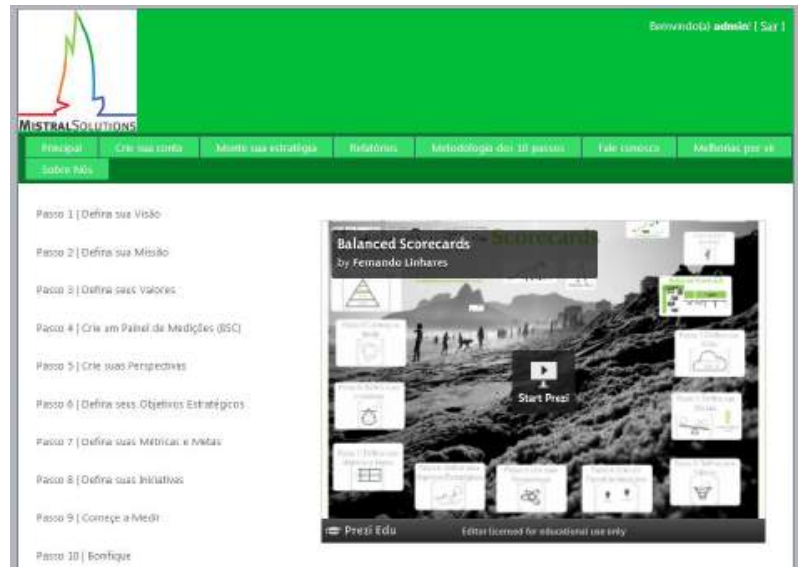

Figure 2: Mistral Solutions System

would lead them to create their BSC, it is not possible to determine the exact number that would provide a label "good" for a fuzzy variable related to monthly income. Renooij and Witteman [17] researched how to relate a numeric scale to words and called it verbal anchors. For a specific value in this scale there is a word that is used as a probability measure for an uncertainty variable. The Figure 3 presents a hybrid scale with verbal anchor and number extracted from [3].

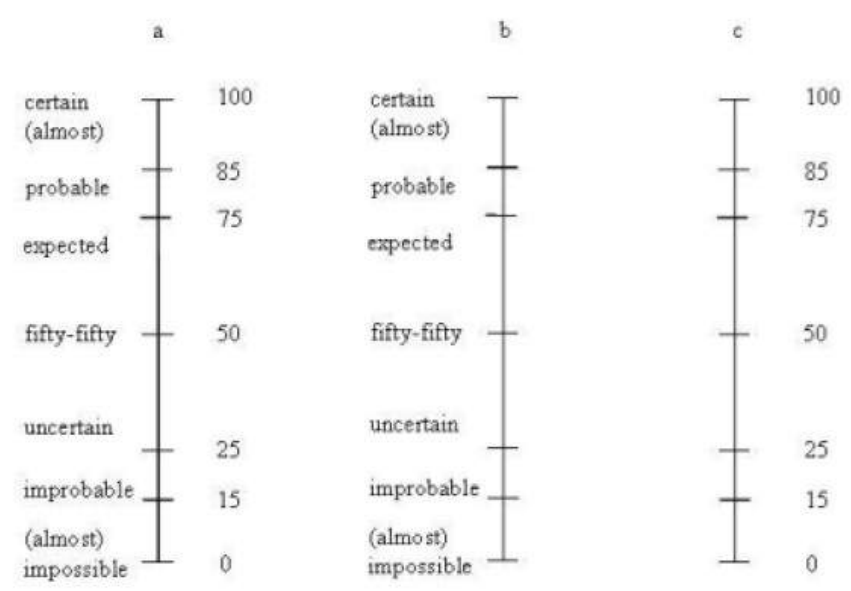

Figure 3: Scale with Verbal Anchors and number

On the Mistral Solutions development we proposed the usage of specific values in a numeric scale as a degree of certainty (Table 2) that may represent answers by the manager.

\subsection{The Mistral Solutions' Fuzzy Architecture}

The knowledge base was constructed with the four classic balanced scorecard perspectives, forty five possible strategic objectives to be selected upon, one hundred and eleven variables, and one hundred and twenty six fuzzy rules 3 . The fuzzy rules developed are presented follows. They were proposed based on the ten years of experience on giving consultancy on BSC and strategic planning by one of the paper's authors[6].
Table 2: Verbal anchors used at Mistral Solutions

\begin{tabular}{|c|c|}
\hline Verbal Anchor & Scale \% \\
\hline Low & 25 \\
\hline Medium & 50 \\
\hline High & 75 \\
\hline Inadequate & 15 \\
\hline OK & 50 \\
\hline Adequate & 85 \\
\hline No & 0 \\
\hline Yes & 100 \\
\hline 1 st & 0 \\
\hline 2nd & 25 \\
\hline 3rd & 50 \\
\hline 4 th & 75 \\
\hline 5 th or more & 100 \\
\hline Up to 10 & 0 \\
\hline Between 10 and 50 & 50 \\
\hline More than 50 & 100 \\
\hline Produtcs & 0 \\
\hline Services & 100 \\
\hline Micro & 0 \\
\hline Small & 40 \\
\hline Medium & 60 \\
\hline Large & 100 \\
\hline 1 & 0 \\
\hline 2 & 25 \\
\hline 3 & 50 \\
\hline 4 & 75 \\
\hline 5 or more & 100 \\
\hline Elementary & 0 \\
\hline High School & 50 \\
\hline Graduated & 100 \\
\hline
\end{tabular}

\subsection{A Empirical Evaluation Based on Three Scenario Cases}

To validate the knowledge base, we ran the system through three scenario cases for three companies in three distinct sectors in Brazil: a court at the public sector, a civil construction material distribution company at the private sector, and a notary at the concession sector. The objecive was to evaluate how the system behaved on a company that aims profit (private sector), an organization that does not aim profit (public sector) and a company which is in the middle way (concession sector). The three companies selected were the most promissing for a validation due to the fact that all of them had knowledge on strategic planning and time available to run all the tests. For the court, the system indicated the initial list of strategic objectives presented in Table 4. The L\&I is a short for the Learning \& Innovations Perspective and I.P. is a short for the Internal Processes Perspective. Considering that all suggested strategic objectives except the last one (do tributes analysis) were accepted by the user in charge of the strategic planning of that court, we infer that this case lead to a success ratio of $87,5 \%$, that is 7 adequate in 8 . The adequacy level measured is the result of fuzzy rules evaluation leading to each specific strategic objective as a system output. The higher the adequacy value, 
Table 3: Some of the rules used at Mistral Solutions

\begin{tabular}{|l|}
\hline Rule \\
\hline IF (Revenues IS Low) OR (Profit IS Low) THEN Dis- \\
\hline
\end{tabular} cover new sources of sales IS High

IF (Revenues IS) OR (Profit IS Medium) THEN Discover new sources of sales IS Medium

IF (Revenues IS High) OR (Profit IS High) THEN Discover new sources of sales IS Low

IF (ROI IS Low) AND (Return on Assets (ROA) IS Low) AND (Revenues IS Low) AND (Profit IS Low) AND (IS Costs High) AND (customers Quantity IS Low) THEN evaluate the possibility of selling the company IS High

IF (Revenue IS Medium) OR (Income IS Low) THEN evaluate the possibility of selling the company IS Medium IF (Revenues IS High) OR (Income IS High) THEN evaluate the possibility of selling the company IS Low

IF (measured customer satisfaction IS No) OR (customer satisfaction IS Low) THEN Increase customer satisfaction IS High

IF (customer satisfaction IS Medium) THEN Increase customer satisfaction IS Medium

IF (customer satisfaction IS High) THEN Increase customer satisfaction IS Low

IF (measured customer satisfaction IS No) THEN Measure customer satisfaction IS High

IF (measured customer satisfaction IS Yes) THEN Measure customer satisfaction IS Low

IF (Everyone knows what to do IS No) AND (Work is documented IS No) THEN Map key processes of the company IS High

IF (Everyone knows what to do IS Yes) OR (Work is documented IS Yes) THEN processes Map key IS Medium company

IF (Everyone knows what to do IS Yes) AND (Work is documented IS Yes) THEN Map Company key processes IS Low

IF (Profit IS Low) AND ((Measure results IS No) OR (IS Controls No) metrics) THEN IS create budget system High

IF (Profit IS Medium) AND (measure results IS Yes) THEN IS create budget system Medium

IF (Profit IS High) AND (measure results IS Yes) AND (Controls metrics IS Yes) THEN IS create budget system Low

IF (Quantity employees IS 30) AND (number hierarchical levels IS 3) AND (There IS no job descriptions) THEN Create competency map IS High

IF (Quantity employees IS 10-30) AND (number hierarchical levels IS 2) AND (There IS no job descriptions) THEN Create competency map IS Medium

IF (Quantity employees IS 10) AND (number hierarchical levels IS 2) AND (There IS no job descriptions) THEN Create competency map IS Low

IF (Measures employees satisfaction IS No) THEN Measure employee satisfaction IS High

IF (Measures employees satisfaction IS Yes) THEN Measure employee satisfaction IS Low

IF (Measures employees satisfaction IS No) AND (Porte company IS micro) THEN Measure employee satisfaction IS Medium
Table 4: Results for a Court at Public Sector

\begin{tabular}{|l|l|c|}
\hline Perspective & Strategic Objective & Adequacy \\
\hline L\&I & Assemble innovation pipeline & 49,90 \\
\hline L\&I & Create bonus program & 50,00 \\
\hline Clients & Increase customer satisfaction & 50,00 \\
\hline Clients & Develop new sales channel & 50,00 \\
\hline I.P. & Create new budget system & 50,00 \\
\hline I.P. & Improve internal processes & 50,00 \\
\hline Financial & Create new point of sales & 89,17 \\
\hline Financial & Do tributes analysis & 89,17 \\
\hline
\end{tabular}

Table 5: Results for Civil Construction Company at Private Sector

\begin{tabular}{|l|l|c|}
\hline Perspective & Strategic Objective Suggested & Adequacy \\
\hline L\&I & Measure employee satisfaction & 89,17 \\
\hline L\&I & Create training program & 50,00 \\
\hline Clients & Measure customer satisfaction & 89,17 \\
\hline Clients & Increase customer satisfaction & 64,40 \\
\hline I.P. & Automate key processes at company & 89,17 \\
\hline I.P. & Analyze internal policies & 64,88 \\
\hline Financial & Create new point of sales & 89,17 \\
\hline Financial & Reduce costs & 89,17 \\
\hline
\end{tabular}

the better.

For the civil construction company, the respondent ran the system and it indicated the initial list of strategic objectives presented in Table 5. All these strategic objectives were analyzed by the respondent as valid, leading to a success ratio of $100 \%$.

For the notary, the respondent ran the system and it indicated the initial list of strategic objectives presented in Table 6. All of them, except the first one (Create bonus program) were analyzed as valid resulting in a success ratio of $87,5 \%$.

\section{CONCLUSIONS}

Firstly, the Mistral Solutions system was publicized in the portal www.mistralsolutions.com.br to be accessed by managers interested in strategic planning. Twenty one companies accessed this portal and responded to the survey generate one hundred and seventy six cases that helped on devel-

Table 6: Results for a Notary at Concession Sector

\begin{tabular}{|l|l|c|}
\hline Perspective & Strategic Objective Suggested & Adequacy \\
\hline L\&I & Create bonus program & 50,00 \\
\hline L\&I & Improve internal communication & 49,90 \\
\hline Clients & Develop new sales channel & 50,00 \\
\hline Clients & Go for voice of costumer & 50,00 \\
\hline I.P. & Map key processes & 89,17 \\
\hline I.P. & Improve internal processes & 67,16 \\
\hline Financial & Go for tributes analysis & 89,17 \\
\hline Financial & Reduce costs & 89,17 \\
\hline
\end{tabular}


oping the Mistral Solutions system. Secondly, a BSC specialist did a empirical evaluation that consist in run the system for companies that have strategic objectives based on the BSC methodology, and analyzed the strategic objectives suggested by the Mistral Solution to see a fit with the company's actual objetives. Thirdly, the Mistral Solutions was applied to the three case study reported and it performed best with private sector institutions.

We conclude that we are on the right track using fuzzy in order to express the lack of data from companies when answering a series of questions related to strategy. On the other hand, we believe that there is room for improvement on validating the results obtained and also on building a stronger knowledge base, offering more strategic objectives for managers to choose.

\section{REFERENCES}

[1] W.-C. C. Amy H.I. Lee and C.-J. Chang. A fuzzy ahp and bsc approach for evaluating performance of it department in the manufacturing industry in taiwan. Expert Systems with Applications, 34:96-107, 2006.

[2] U. Cebeci. Fuzzy ahp-based decision support system for selecting erp systems in textile industry by using balanced scorecard. Expert Systems with Applications, pages 8900-8909, 2009.

[3] S. R. Cilia Witteman and P. Koele. Medicine in words and numbers: a cross-sectional survey comparing probability assessment scales. BMC Medical Informatics and Decision Making, 2007.

[4] K. P. Coyne and S. Subramaniam. Bringing discipline to strategy. The McKinsey Quarterly, 1996(4):14-25, April 1996.

[5] G. Creamer and Y. Freund. Learning a board balanced scorecard to improve corporate performance. Decision Support Systems, 49:365-385, 2010.

[6] F. de Albuquerque Linhares. Utilização de Âncoras Verbais e Raciocínio Fuzzy na Construção de Mapas Estratégicos da Metodologia Balanced Scorecard. M.Sc., Universidade de Brasília, Brasilia, Brazil, 2015.

[7] A. Humphrey. Swot analysis for management consulting. Stanford Research Institute (SRI International) Alumni Newsletter, pages 7-8, December 2005.

[8] R. S. Kaplan and D. P. Norton. The balanced scorecard - measures that drive performance. Harvard Business School Press, 1992.

[9] R. S. Kaplan and D. P. Norton. The Balanced Scorecard: Translating Strategy into Action. Harvard Business Review Press, 1996.

[10] R. S. Kaplan and D. P. Norton. The Execution Premium: Linking Strategy to Operations for Competitive Advantage. Harvard Business Review Press, Boston, Massachusetts, 2008.

[11] W. C. Kim and R. Mauborgne. Blue ocean strategy. Harvard Business Review, 2004(10):1-10, 2004.

[12] C. K. Kwong and H. Bai. A fuzzy ahp approach to the determination of importance weights of customer requirements in quality function deployment. Journal od Intelligent Manufacturing, pages 367-377, 2002.

[13] M. A. Meysam Shaverdi and S. F. Tafti. Combining fuzzy mcdm with bsc approach in performance evaluation of iranian private banking sector. Hindawi
Publishing Corporation - Advances in Fuzzy Systems, 2011:12, 2011.

[14] M. A. A. Mohammad Abdolshaha, Mojtaba Javidniab and M. Eslamic. An integrated approach to analyze strategy map using bsc - fuzzy ahp: A case study of auto industry. Management Science Letters, 2:705-712, 2012.

[15] H. R. Morteza Mousakhani and N. Hamidi. Hospitals ranking using fuzzy analytic hierarchy process balanced score card. Asian Journal of Management Research, page 13, 2010.

[16] M. E. Porter. The five competitive forces that shape strategy. Harvard Business Review, 2008(1):1-10, January 2008.

[17] S. Renooij and C. Witteman. Talking probabilities: communicating probabilistic information with words and numbers. International Journal of Approximate Reasoning, 22(3):169-194, 1999.

[18] M. J. Seyed Abdollah Heydariyeha and A. Mehdiabadib. A new approach to analyze strategy map using an integrated bsc and fuzzy dematel. Management Science Letters, 2:161-170, 2012.

[19] W. Thanaraksakul and B. Phruksaphanrat. Supplier evaluation framework based on balanced scorecard with integrated corporate social responsibility perspective. Proceedings of the International MultiConference of Engineers and Computer Scientists, II:6, 2009. 